\title{
Effects of Transforaminal Injection for Degenerative Lumbar Scoliosis Combined with Spinal Stenosis
}

\author{
Hee-Seung Nam, M.D., Yong Bum Park, M.D. ${ }^{1}$ \\ Department of Rehabilitation Medicine, Hallym University College of Medicine, Seoul 134-701, \\ ${ }^{1}$ Sanggye Paik Hospital, Inje University College of Medicine, Seoul 139-707, Korea
}

Objective The objectives of this study were to clarify the short-term effects of transforaminal epidural steroid injection (TFESI) for degenerative lumbar scoliosis combined with spinal stenosis (DLSS), and to extrapolate factors relating to the prognosis of treatment.

Method Thirty-six patients with lumbar radicular pain from DLSS were enrolled. Subjects were randomly assigned to one of two groups (steroid or lidocaine group). We compared the effect of pain suppression at 2, 4 and 12 weeks after the procedure between the two groups. Radiographic analysis included measurement of the Cobb's angle, the upper endplate obliquities of L3 and L4, and maximal lateral olisthy between two adjacent lumbar vertebrae. Sagittal plane measurement included lumbar lordosis, and thoracolumbar kyphosis. Statistical analysis of both radiographic and clinical parameters along with treatment outcome was performed to determine any significant correlations between the two.

Results There were no significant differences in the demographic data, initial visual analogue scale (VAS) or Oswestry disability index (ODI) between the steroid group $(\mathrm{n}=17)$ and the lidocaine group $(\mathrm{n}=19)$. Two, 4, and 12 weeks after injection VAS, ODI showed a significantly greater improvement in the steroid group compared to the lidocaine group $(\mathrm{p}<0.05)$. The radiographic and clinical parameters were not significantly correlated with treatment outcome.

Conclusion Our findings suggest that fluoroscopic transforaminal epidural steroid injections appear to be an effective non-surgical treatment option for patients with degenerative lumbar scoliosis combined with spinal stenosis (DLSS) and radicular pain.

Key Words Degenerative, Scoliosis, Steroid, Stenosis, Transforaminal

Received August 17, 2010; Accepted January 3, 2011

Corresponding author: Yong Bum Park

Department of Rehabilitation Medicine, Sanggye Paik Hospital, Inje University College of Medicine, 761-1, Sanggye 6,7 dong, Nowon-gu, Seoul 139-707, Korea

Tel: +82-2-950-1390, Fax:+82-2-935-3076, E-mail: swc328@naver.com

(c) This is an open-access article distributed under the terms of the Creative Commons Attribution Non-Commercial License (http://creativecommons.org/ licenses/by-nc/3.0) which permits unrestricted noncommercial use, distribution, and reproduction in any medium, provided the original work is properly cited. Copyright $\odot 2011$ by Korean Academy of Rehabilitation Medicine

\section{INTRODUCTION}

Radicular pain occurs due to an ectopic discharge physiologically generated in either the dorsal root or the dorsal root ganglion. An important cause of radicular pain is mechanical compression exerted by degenerative changes in the facet joint, the posterior longitudinal ligament or the herniated disc. Another cause is 
chemical irritation produced by phospholipase A2 or substance $\mathrm{P}$ secreted from the prolapsed intervertebral disc. As a result, they contribute to pain mechanisms by triggering venous congestion and/or neural edema around the nerve root. ${ }^{1-3}$ The pathogenesis of radicular pain caused by lumbar spinal stenosis is difficult to explain by a unique factor, because it is associated with a variety of mechanisms, including inflammation, venous congestion, mechanical compression, and circulation disturbance. ${ }^{4,5}$ Epidural steroid injections (ESIs) have been used for the treatment of radicular pain, although their success rate has been reported to vary between $20 \%$ and $100 \%{ }^{6}$ There are several possible reasons for such inconsistent results: (1) The treatment targeted a diverse range of symptoms, including primary axial pain, primary radicular pain, and radiculopathy, which had been elicited by many different causes (e.g., disc herniation, spinal stenosis, spondylolisthesis, and failed back surgery syndrome); (2) The authors applied an indiscriminate treatment, without distinguishing between several steroid injection methods (e.g., caudal approach, interlaminar approach, and transforaminal approach); and (3) Steroid injections were used in different doses, from different formulations and with different needle sizes. ${ }^{7}$ In addition, their accuracy may be limited because the cited results were obtained from injection procedures performed blindly without using fluoroscopy control. ${ }^{8}$ Moreover, there are only a few studies in the literature that compare different causes or different injection approaches when assessing the effects of steroid injections for the treatment of radicular pain. This makes it more difficult to determine the specific injection treatment options required by individual patients, as well as their characteristics.

Unlike adolescent idiopathic scoliosis, degenerative lumbar scoliosis is usually accompanied by spinal stenosis. Therefore, it becomes increasingly prevalent in the elderly, which included population older than 50 years of age. ${ }^{9,10}$ Most patients with degenerative lumbar scoliosis combined with spinal stenosis also present with other symptoms, such as neurogenic claudication, radiating pain, and/or axial back pain..$^{10-12}$ So far, epidural injections have not drawn much attention as an alternative approach for the treatment of lumbar radicular pain caused by degenerative lumbar scoliosis combined with spinal stenosis. Simotas et al. ${ }^{13}$ studied the effects of epidural injections and other conservative treatments in patients with spinal stenosis and neurogenic claudication. They reported that the treatments were less effective in cases of combined scoliosis, as seen on radiographs. However, their study could not accurately assess the effects of epidural injections because it was performed in a small number of subjects $(n=15)$ while receiving different additional conservative treatments. Cooper et al. ${ }^{7}$ conducted a retrospective study to investigate the effects of transforaminal injections on the radiculopathy produced by degenerative lumbar scoliosis with spinal stenosis. They reported a successful treatment effect in 59.6 percent of the studied subjects at week 1 of the injection, 55.8 percent at month 1, 37.2 percent at year 1 , and 27.3 percent at year 2 .

The primary objective of this study was to prospectively examine the effects of transforaminal steroid injections on radicular pain elicited by degenerative lumbar scoliosis combined with spinal stenosis. In addition, we investigated the relationship between radiation indicators of scoliosis and patient characteristics that could influence the treatment effects.

\section{MATERIALS AND METHODS}

\section{Subjects}

The subjects of this study were aged 50 years and older and selected from patients who visited our hospital's Department of Physical Medicine and Rehabilitation with complaints of radiating pain, between January 1 , 2009 and June 31, 2010. We took their history and performed physical examination in all our patients. In the present study, inclusion criteria were as follows: 1) cases with pain that increased with lumbar extension and decreased with lumbar flexion; 2) patients with radiating pain present at least below the knee joint; and 3) cases with a thoracolumbar scoliosis greater than 10 degrees, visible on the standard $\mathrm{Rx}$ in the standing anteriorposterior (AP) and lateral views of the whole spine, including the hip joint and the cervical spine, or in the standing lateral bending views of the lumbar spine. The subjects were patients who were found to have spinal stenosis on both CT and MRI examinations of the lumbar spine performed for the nerve-root location in those cases. The exclusion criteria were as follows: 1 ) patients with any systemic inflammatory disease or diabetes; 2) 
patients taking anticoagulant medication; 3) patients who had previously experienced side effects from the use of lidocaine or contrast dye; 4) patients with any known or suspected infectious disease; 5) patients who found it difficult to regularly visit the hospital because of general bad health; 6) patients with a skin disorder rending them unsuitable for injection administration on the injection site; 7) cases with a mental health problem who were unable to complete a questionnaire; 8) patients who had received a steroid injection in the three months prior to the beginning of the study; 9) cases with degenerative spondylolisthesis, osteoporosis or compression fracture; and 10) patients who had received surgical treatment of the thoracolumbar region or cases with cancer metastasis to the thoracolumbar site or with spinal deformity caused by metabolic disease. Degenerative lumbar scoliosis patients were included in the study only when their radicular pain resulted from lateral foraminal stenosis. In contrast, patients with spinal stenosis or neurogenic claudicaiton were excluded from the study. We also excluded cases with neurological symptoms such as cauda equine syndrome, and patients that needed nonsteroidal anti-inflammatory drugs other than acetaminphen or low dose aspirin, as well as those who continued to receive other conservative treatments such as physiotherapy over the clinical trial period. This could influence the assessment of the overall curative value during the clinical period.

\section{Assignment of subjects to the study groups}

The subjects were divided into two groups and treated with one of two different injection drugs. For the steroid group, the injection site was highlighted on the radioscopy with 1 cc of nonionic contrast (Omnipaque 300; GE Health care, Shanghai, Ireland) and a mixture of 1.5 cc $0.5 \%$ lidocaine and $20 \mathrm{mg}(0.5 \mathrm{cc})$ triamcinolone was administered. In the control group, $1 \mathrm{cc}$ of nonionic contrast (Omnipaque 300) was injected to visualize the injection site and each subject received a transforaminal injection of 2 cc $0.5 \%$ lidocaine without triamcinolone. Block randomization was used to group the subjects and allocate them to each of the groups. With a block size of four for two arms (A and B), six possible combinations of blocks consisting of two As and two Bs were produced: $\mathrm{AABB}, \mathrm{ABAB}, \mathrm{BAAB}, \mathrm{BABA}, \mathrm{BBAA}$, and $\mathrm{ABBA}$. A random number sequence was used to select a particular block, thus determining the allocation order for the first four subjects. Similarly, the next four patients were allocated to the treatment group, in the order required by the next randomly selected block.

\section{Injection approaches and their effects}

The transforaminal approach: Each subject was placed in the prone position with a pillow under the abdomen to reduce lumbar lordosis. A Scotty dog image was used to identify the desired lumbar region. The C-arm (KMC 950, KOMED, Kwangju, Kyunggi, Korea) was adjusted to align with the inferior endplate of the spine and rotated by 15-30 degrees to an oblique view, so that the Scotty dog image became visible. The target region was disinfected, and a 22-gauge 3.5-inch spinal needle (Spinocan ${ }^{\circledR}$, BRAUN, Melsungen, Germany) was used. To avoid the
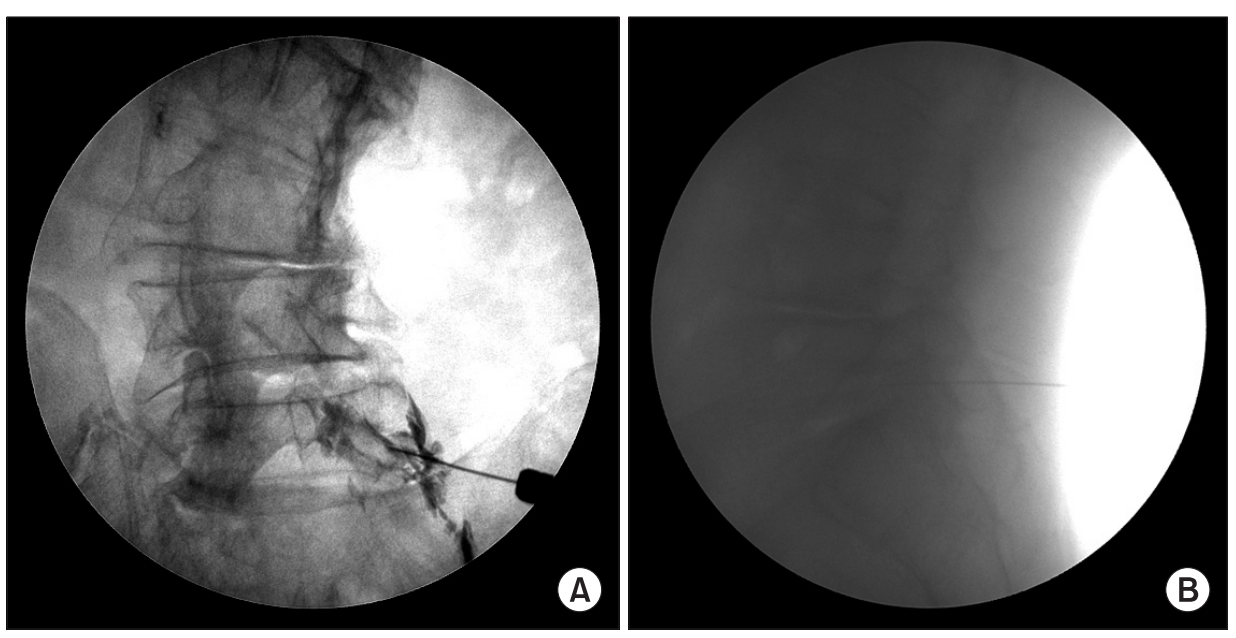

Fig.1. Fluoroscopically guided transforaminal epidural injection. (A) anteroposterior view, (B) lateral view. 
nerve roots emerging from the spinal cord, the needle was advanced into either the right inferior aspect of the spinal pedicle or the inferolateral portion (safe triangle) of the pars interarticularis, towards the superior aspect of the intervertebral foramen. When the needle tip reached the inferolateral border, the $\mathrm{C}$-arm was rotated to obtain lateral images. Then the needle was slowly advanced towards the anterosuperior aspect of the foramen. Once the needle was placed in the final position, a fine aspiration was performed, to check for the presence of blood. One cc of nonionic contrast dye was administered under real-time fluoroscopic imaging to determine if the drug was injected into the anterior epidural space. After the administration of the contrast dye, anteroposterior and lateral radiographs were taken and a $2 \mathrm{cc}$ dose of the drug solution was injected (Fig. 1).

Comparison of the injection effects between the two groups: Pain scores on the visual analogue scale (VAS) were recorded at baseline and at weeks 2, 4 and 12 of treatment, for comparison of the treatment effects of injections. A 100-mm horizontal graded scale was presented to the patients. Pain was rated from no pain $=0$ to the most severe pain $=10$, and the subjects were asked to indicate their pain on the scale. The degrees of physical disability were measured using the Oswestry Disability Index (ODI). Physical disability was noted as percentage values, from no disability $=0 \%$ to the most severe disability $=100 \%$. At week 12 , the subjects were asked to rate their satisfaction with the treatment, as follows: "no residual pain (excellent)," "improvement of pain symptoms by more than 50\% (good)," "improvement of pain symptoms by less than $50 \%$ (fair)," or "no improvement of pain (poor)." Reponses of "excellent" and "good" were considered to represent pain relief.

Injection frequency and time intervals: Two weeks after the first injection treatment, during the outpatient visit, if satisfaction with the treatment was rated as "no improvement of pain (poor)" or there was no change in the VAS and ODI scores, the patients were excluded from the study. However, one more injection was given one week thereafter, if there was only partial effect in cases of "improvement of pain symptoms by less than 50\% (fair)" in treatment satisfaction, less than $50 \%$ in the VAS, and less than $30 \%$ in the ODI. The cases of more than $50 \%$ in the VAS, more than $30 \%$ in the ODI, as well as no residual pain (excellent) and improvement of pain symptoms by more than $50 \%$ (good) in treatment satisfaction were just followed up without additional injection.

Correlations of the treatment effects with different factors

The treatment was successful when the patients rated their satisfaction level as "no residual pain" or "improvement of pain symptoms by more than $50 \%$ " 12 weeks after the first injection treatment and when they showed an improvement of more $40 \%$ in the VAS and an improvement of more than $20 \%$ in the ODI at the same point in time. The study examined the correlations between these measurements and the patients' age, pain duration, sex, or pre-injection radiation indicator of degenerative lumbar scoliosis. For the radiological analysis, we took the standing AP and lateral views of the whole spine, including the hip joint and cervical spine, and both lateral bending views of the lumbar spine, using a $14 \times 36$ inch cassette. Then we measured the lumbar spine scoliosis angle with the Cobb angle method and the axial rotation angle of the spinal body with the method of Nash and $\mathrm{Moe}^{14}$ for the measurement of spinal rotation. The lateral shift and the L3 and L4 endplate obliquity angles were measured using the method of Schwab et al. ${ }^{15}$ In addition, from the lateral views, we measured the lordosis angle between the upper margin of $\mathrm{Ll}$ and the upper margin of S1, and the thoracolumbar kyphosis angle between the upper margin of T11 and the lower margin of L1.

\section{Statistical analysis}

The chi-square test and Wilcoxon's rank sum test were used to compare the two investigated groups in terms of age, sex, body mass index, pain duration, injection frequency, and radiation indicators. The independent t-test was conducted to compare the ODI and the VAS scores differences between the two groups, at each treatment time point. A repeated measures analysis of variance (ANOVA) was used to assess the injection effects over time, and the Bonferroni's correction was applied for post hoc tests. In determining the treatment effects, the chi-square test was used to compare the differences between the two groups, in terms of success rate and patient satisfaction index. A logistic regression analysis was employed to examine the correlations between the post-injection clinical results and the patients' age, pain 
duration, sex, or radiation indicators of degenerative lumbar scoliosis. Data was statistically analyzed with a significance level of $\mathrm{p} \leq 0.05$ using the SAS Enterprise Guide version 4.1 (4.1.0.471) software.

\section{RESULTS}

\section{General characteristics}

This study included a total number of 36 subjects who were divided into two groups: the steroid injection group $(n=17$, mean age $=75.24 \pm 5.27$ years $)$ and the lidocaine injection group $(\mathrm{n}=19$, mean age $=71.58 \pm 9.55$ years). There was no statistically significant difference between the two groups in the following measurements: male-female ratio, body mass index, pain duration, and injection frequency. There was also no statistically significant difference in the causes of the nerve root stenosis, as seen on both thoracolumbar spine MRI and CT scans (Table 1, 2).

Table1. Comparison of Steroid and Lidocaine Patient Groups

\begin{tabular}{|c|c|c|c|}
\hline & $\begin{array}{l}\text { Steroid group } \\
\quad(n=17)\end{array}$ & $\begin{array}{c}\text { Lidocaine } \\
\text { group }(n=19)\end{array}$ & p-value \\
\hline Female & $13(76.5 \%)$ & $14(73.7 \%)$ & 0.847 \\
\hline Age (years) & $75.24 \pm 5.27$ & $71.58 \pm 9.55$ & 0.349 \\
\hline Pain duration (mo) & $7.71 \pm 2.59$ & $6.74 \pm 2.83$ & 0.201 \\
\hline BMI $\left(\mathrm{kg} / \mathrm{m}^{2}\right)$ & $23.37 \pm 2.55$ & $22.95 \pm 1.75$ & 0.409 \\
\hline $\begin{array}{l}\text { Number of } \\
\text { patients with } \\
1 \text { injection }\end{array}$ & $8(42.1 \%)$ & $11(57.9 \%)$ & \\
\hline $\begin{array}{l}\text { Number of } \\
\text { patients with } \\
2 \text { injection }\end{array}$ & $9(52.9 \%)$ & $8(47.1 \%)$ & 0.376 \\
\hline $\begin{array}{l}\text { Number of } \\
\text { S1 injection }\end{array}$ & $2(11.7 \%)$ & $3(15.8 \%)$ & \\
\hline $\begin{array}{l}\text { Number of } \\
\text { L5-S1 injection }\end{array}$ & $6(35.4 \%)$ & $8(42.1 \%)$ & \\
\hline $\begin{array}{l}\text { Number of } \\
\text { L4-5 injection }\end{array}$ & $7(41.2 \%)$ & $7(36.8 \%)$ & \\
\hline $\begin{array}{l}\text { Number of } \\
\text { L3-4 injection }\end{array}$ & $2(11.7 \%)$ & $1(5.3 \%)$ & 0.275 \\
\hline
\end{tabular}

Values are shown as mean \pm standard deviation BMI: Body mass index

Statistical significance between the two groups, calculated using Wilcoxon's rank sum test or Chi-square test ${ }^{*} \mathrm{p}<0.05$

\section{Patient flow}

A total number of 61 patients were enrolled, whereas 13 dropped out of the study according to the exclusion criteria. One subject in the steroid group and two subjects in the lidocaine group were excluded from the study because they showed no effect during the follow-up. In the middle of the study, two subjects in the steroid group and one subject in the lidocaine group were transferred to a different medical department for surgical treatment. We eliminated two patients from the lidocaine group for taking an anti-inflammatory drug different from acetaminophen during the study. Four other patients were excluded halfway because it became difficult for them to regularly visit the hospital.

Table 2. Comparison of Steroid and Lidocaine Groups in Radiologic Findings

\begin{tabular}{|c|c|c|c|}
\hline & $\begin{array}{c}\text { Steroid } \\
\text { group }(n=17)\end{array}$ & $\begin{array}{c}\text { Lidocaine } \\
\text { group }(n=19)\end{array}$ & p-value \\
\hline Cobb's angle & $16,79 \pm 6.81$ & $15.14 \pm 3.44$ & 0.751 \\
\hline $\begin{array}{l}\text { Lateral olisthesis } \\
(\mathrm{mm})\end{array}$ & $5.42 \pm 2.11$ & $5.35 \pm 2.12$ & 0.975 \\
\hline $\begin{array}{l}\text { Endplate } \\
\text { obliquities of } \\
\text { L3 angle }\end{array}$ & $8.49 \pm 4.72$ & $8.18 \pm 4.43$ & 0.775 \\
\hline $\begin{array}{l}\text { Endplate } \\
\text { obliquities of } \\
\text { L4 angle }\end{array}$ & $8.31 \pm 4.57$ & $9.18 \pm 3.96$ & 0.505 \\
\hline $\begin{array}{l}\text { Thoracolumbar } \\
\text { kyphosis }\end{array}$ & $8.36 \pm 4.79$ & $8.34 \pm 4.45$ & 0.924 \\
\hline Lordosis angle & $33.37 \pm 8.51$ & $32.12 \pm 6.41$ & 0.680 \\
\hline $\begin{array}{l}\text { Vertebral rotation } \\
\text { grade (Neutral/I/ } \\
\text { II/III/IV) }\end{array}$ & $\begin{array}{c}\mathrm{n}=17 \\
(4 / 10 / 1 / 1 / 1)\end{array}$ & $\begin{array}{c}n=19 \\
(4 / 12 / 1 / 1 / 1)\end{array}$ & 0.999 \\
\hline \multicolumn{4}{|l|}{ Radiologic finding } \\
\hline $\begin{array}{l}\text { Hypertrophic facet } \\
\text { osteoarthritis }\end{array}$ & 5 & 6 & \\
\hline Pedicular kinking & 8 & 10 & \\
\hline $\begin{array}{l}\text { Posterolateral } \\
\text { verterbral body } \\
\text { spur }\end{array}$ & 3 & 2 & \\
\hline $\begin{array}{r}\text { Subluxation of } \\
\text { superior facet }\end{array}$ & 1 & 1 & 0.254 \\
\hline
\end{tabular}

Values are shown as mean \pm standard deviation

Statistical significance between the two groups, calculated using Wilcoxon's rank sum test or Chi-square test ${ }^{*} \mathrm{p}<0.05$ 


\section{Comparison of the treatment effects}

At baseline, there was no difference between the two groups in the ODI and VAS scores. However, at weeks 2, 4 and 12 of treatment, the steroid group showed significant improvements compared to the lidocaine group (Fig. 2, 3). For treatment effectiveness over time after the injection procedure, both groups showed a significant decrease in the VAS score compared to baseline. This effect was maintained until weeks 2, 4 and 12 after initiation of treatment (Fig. 2). The ODI also significantly improved in both groups, compared to baseline. The improvement was continued until weeks 2, 4 and 12, as well (Fig. 3). At week 12, the treatment effect was assessed as successful in 13 steroid group subjects and 8 lidocaine group subjects. Consequently, the steroid group achieved a statistically higher success rate than the lidocaine group. Patient satisfaction also rated significantly higher in the steroid group $(\mathrm{p}<0.05)$.

Treatment effects and correlations between the patient factors and the radiation indicators

Treatment success was defined as an improvement of more than $40 \%$ in the VAS score and more than $20 \%$ in the ODI score, as well as the patient satisfaction level of "no residual pain (excellent)" or "improvement of pain symptoms by more than $50 \%$ (good)," at week 12 after the injection treatment. In the analysis based on this definition, we found no correlation between the patient factors and radiation indicators (Table 3 ).

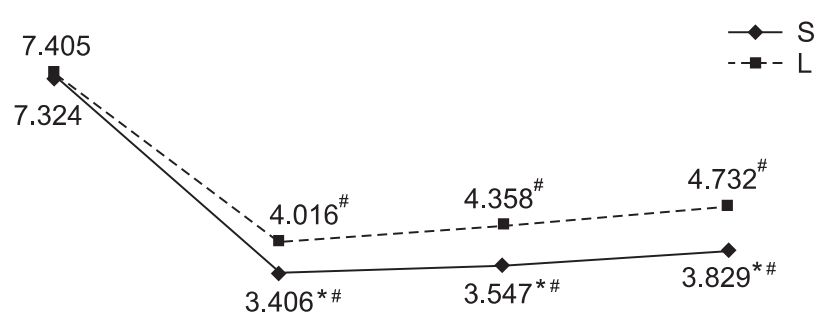

VAS I

VAS $2 \mathrm{~W}$

VAS $1 \mathrm{M}$

VAS $3 \mathrm{M}$

Fig. 2. Comparative response from VAS pre-injection, 2 weeks, 1 month, 3 months for steroid group and lidocaine group. *statistically significant at $\mathrm{p}<0.05$ within groups, "statistically significant at $\mathrm{p}<0.05$ within intergroup. VAS: Visual analogue scale, S: Steroid group, L: Lidocaine group.

\section{DISCUSSION}

Degenerative lumbar scoliosis is usually accompanied by axial back pain and spinal stenosis. Unlike the common symptoms of spinal stenosis, axial back pain is persistent when sitting and at rest. ${ }^{16}$ It is known that radiating pain is mostly caused by nerve compression resulting from foraminal stenosis, which, is caused by the contact of the facet joint after the intervertebral disc collapses from disc herniation, and from lateral reposition of the vertebral body. ${ }^{17-19}$ Except for this mechanical compression, the causes for radicular pain of spinal stenosis produced by degenerative lumbar scoliosis cannot be explained by a unique theory. Therefore, the radicular pain is associated with various mechanisms, such as inflammatory changes around the nerve roots, venous congestion, or circulation disturbance. ${ }^{4,5}$ When injected into the human body, steroids ease pain by inhibiting prostaglandin synthesis, blocking the conduction of nociceptive C-fibers, and controlling the edema around nerve roots. ${ }^{20-22}$ For this reason steroid injections are used in patients diagnosed with radicular pain elicited by spinal stenosis.

To date, there are only few studies on epidural steroid injections in patients with spinal stenosis. Hoogmartens and Morelle ${ }^{23}$ performed epidural steroid injections blindly (without radioscopy control), using the caudal approach, and reported the following treatment effects: $32 \%$ good, $16 \%$ average, and $52 \%$ bad. In the retrospective study conducted by Rosen et al., ${ }^{24}$ steroids were injected without radioscopy control with the interlaminar ap-

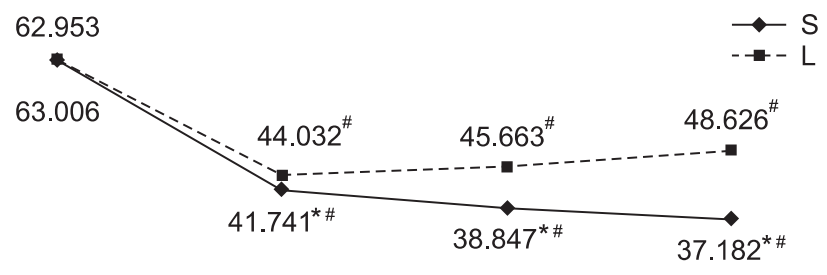

ODI ODI $2 \mathrm{~W}$ ODI 1M ODI 3M

Fig. 3. Comparative response from ODI pre-injection, 2 weeks, 1 month, 3 months for steroid group and lidocaine group. *statistically significant at $\mathrm{p}<0.05$ within groups, "statistically significant at $\mathrm{p}<0.05$ within intergroup. ODI: Oswestry disability index, S: Steroid group, L: Lidocaine group. 
Table 3. Multiple Logistic Regression Analysis for Possible Outcome Predictors for Injection Effectiveness at Shortterm Follow-up

\begin{tabular}{lccc}
\hline \multicolumn{1}{c}{ Factor } & OR & 95\% CI & p-value \\
\hline SEX & 0.706 & $0.49-10.188$ & 0.798 \\
\hline Age $($ years $)$ & 0.869 & $0.726-1.041$ & 0.127 \\
BMI $\left(\mathrm{kg} / \mathrm{m}^{2}\right)$ & 0.833 & $0.515-1.346$ & 0.456 \\
Duration & 1.062 & $0.708-1.593$ & 0.772 \\
Cobb's angle & 0.988 & $0.752-1.299$ & 0.934 \\
Thoracolumbar kyphosis & 0.962 & $0.752-1.232$ & 0.761 \\
\hline Lordosis & 1.071 & $0.930-1.234$ & 0.338 \\
\hline Lateral olisthesis & 1.635 & $0.638-4.191$ & 0.306 \\
$\begin{array}{l}\text { Endplate obliquities of } \\
\text { L3 angle }\end{array}$ & 1.061 & $0.80-1.394$ & 0.674 \\
$\begin{array}{l}\text { Endplate obliquities of } \\
\text { L3 angle }\end{array}$ & 0.688 & $0.444-1.068$ & 0.096 \\
\hline OR: Odd & & & \\
\hline
\end{tabular}

OR: Odds ratio, 95\% CI: 95\% Confidence interval, BMI: Body mass index

$\mathrm{p}<0.05$

proach. Pain relief was reported in $66 \%$ of the patients at 2 months and in $25 \%$ of the patients 8 months after initiation of treatment. These studies were conducted in a blind interlaminar or caudal approach without the aid of an image-enhancing device. Therefore, they have some clear limitations with regards to the accuracy of injection. It is impossible to target a specific lesion region without visual control. It has been demonstrated that blind epidural steroid injections, even done by very skilled doctors, showed over $25 \%$ probability for the needle to be improperly positioned. ${ }^{7}$ In the study conducted by Delport et al. ${ }^{25}$ using an image-enhancing device instead of the blind procedure, after steroid was injected with the caudal and interlaminar approaches, one third of the patients demonstrated pain relief and about half of them showed some improvement. In addition, Riew et al. ${ }^{26}$ conducted a prospective, randomized, double-blind study and reported that when transforaminal steroid injections were given in spinal stenosis patients using the $\mathrm{C}$-arm, some clinical improvement was found during the follow-up period of 15-28 months. Cooper et al. ${ }^{7}$ conducted a retrospective study on the effects of transforaminal steroid injections performed using the $\mathrm{C}$-arm to treat the radiculopathy produced by degenerative lumbar scoliosis combined with spinal stenosis. They reported that at year 2 after injection, successful treatment effects were found in $27.3 \%$ of the patients. Therefore, they concluded that this procedure can be selected as one of the elective non-surgical treatment methods. However, these studies were all retrospective and not conducted within the same patient group. Besides, several methods were attempted for an epidural approach. In addition, the way of checking for the injection effects showed such limitation that it could not discriminate the axial back pain from the radicular pain. Using the prospective randomization design, this study used the lidocaine injection group as a control group. Then we investigated the effects of transforaminal epidural injections performed with the C-arm. Compared with the lidocaine group, the transforaminal epidural injections were statistically more effective, as measured by the VAS score and the functional rating index. Furthermore, during the 3-month follow-up period, continuous improvement was found. This effect of the steroid injections on the radicular pain produced by spinal stenosis may be explained by the fact that an inflammatory reaction by compression is associated with the direct cause for pain, which is mechanical compression. Steroid injections not only reduce the inflammatory reaction, but also block nerve conduction via nociceptive C fibers, thus suppressing the direct pain pathway, and further relieving the symptoms. ${ }^{27}$

Simotas et al. ${ }^{13}$ examined correlations between the effects of non-surgical treatment and several factors in patients with spinal stenosis. They reported that the treatment effects decreased in patients with scoliosis or in old patients. Miyamoto et al. ${ }^{28}$ also reported that the treatment effects decreased in patients with scoliosis, but they found no correlation with age. This study examined correlations between the treatment effects and several factors, including age, gender, body fat percentage disease duration, and the radiation indicators of scoliosis, which were divided into thoracolumbar kyphosis, lordosis, and the Cobbs angle method. As a result, no correlations with the indicators were found. The study by Miyamoto et al. ${ }^{28}$ did not divide its subjects into a group of central stenosis patients with neurogenic claudication and a group of lateral stenosis patients with radicular pain, and the subjects did not receive the same treatment. We consider this as a limitation of the study. We consider that without a good understanding of the causes of pain, such as radicular pain produced by lateral stenosis, the referred pain elicited by facet joint syndrome, visceral 
pain, muscle pain, or lumbar sprain, suitable treatment for diagnosis cannot be given. It may also be difficult to know adequate treatment effects and further, the correlations with several factors. In this study, patients with degenerative lumbar scoliosis were included only when they had radicular pain produced by lateral stenosis. They were excluded when they had central stenosis, such as neurogenic claudication. In relation to the treatment methods, only the transforaminal injection treatment using the $\mathrm{C}$-arm was given and during the trial, patients who took medicine influencing the treatment effects and the conservative treatment were excluded. Thus, the reliability of the study results increased. Cases of degenerative lumbar scoliosis are usually accompanied by severe back pain in addition to lateral stenosis. van $\mathrm{Dam}^{29}$ showed that such back pain resulted mostly from the surrounding muscles, intervertebral disc and facet joint. Pritchett and Bortel ${ }^{30}$ reported that it was associated with the reduction of the lordotic angle. According to the study by Schwab et al., ${ }^{15}$ in the case of adult patients with scoliosis, pain correlated with radiation indicators, and was especially highly associated with the L3 and L4 scoliosis angles, lateral displacement, reduced lumbar lordosis and thoracolumbar kyphotic angle. Accordingly, symptoms of severe back pain, radiating pain, and spinal instability appeared in patients with degenerative lumbar scoliosis. After ending the clinical trials, we performed a lumbar medial branch block in seven patients with combined back pain, and some of them showed improvement. In addition to radicular pain caused by spinal stenosis, patients with degenerative lumbar scoliosis could have back pain due to several reasons, hence they may need treatment for it. This study found no correlations between the treatment effects on radicular pain and the radiation indicators of patients with degenerative lumbar scoliosis. However, referring to the results of the studies described above, it was considered that radiation indicators are associated with back pain. In future work, it will be necessary to study the correlations between the lumbago-related medial branch blocks for the back pain of lumbar scoliosis patients, and conservative treatment results for visceral pain, as well as the radiation indicators mentioned above. In the assessment of the treatment effects done over 12 weeks, the success rate was $76.5 \%$ in the steroid group and $42.1 \%$ in the lidocaine group. In the study by Cooper et al. ${ }^{7}$ the criteria for successful treatment included patient satisfaction index of grades 1-2 and the numeric pain rating of grade 2 or higher. In the study by $\mathrm{Ng}$ et al. ${ }^{31} 20$ $\mathrm{mm}$ reduction in the visual analogous scale and $10 \%$ reduction in the ODI score were found. Compared with those studies, this study judged success or failure based on stricter criteria ("no residual pain" and "improvement of pain symptoms by more than $50 \%$ " as patient satisfaction index, and $40 \%$ VAS and over $20 \%$ ODI improvement). Therefore, we considered the assessment of our results as reliable. Patients who failed conservative treatment could require surgical treatment. Indications of absolute surgical treatment included neurological symptoms like cauda equine syndrome and severe pain that did not respond to conservative treatment. ${ }^{11,12}$ However, most lumbar scoliosis patients are quite old and have cardio pulmonary or heart diseases. They also have severe degenerative deformity of the spine, so it is difficult for them to receive surgery. ${ }^{32}$ In cases of accompanying degenerative neurological disorders, like Alzheimer's disease or Parkinson's disease, it is very difficult to apply rehabilitation treatment after surgery. ${ }^{33}$ Some of the previous studies reported that a key to success of non-surgical treatment for patients with spinal stenosis was an intensive and aggressive initial treatment. ${ }^{13,34,35}$ In particular, Miyamoto et al.$^{28}$ judged the hospitalization treatment of 2-3 weeks as an intensive treatment method and reported that a combination of various non-surgical treatments during this period, like physiotherapy and brace or orthosis wearing, could have synergistic effects. In addition, steroid injections delivered with various approaches could be applied during this intensive treatment period. They suggested that this intensive hospitalization treatment could become an intermediate step between outpatient treatment and surgical treatment. ${ }^{28}$ Therefore, future studies of degenerative lumbar scoliosis patients with spinal stenosis are required to cover outpatient, inpatient and surgical treatments.

In this study, the lidocaine group showed $42.1 \%$ treatment success. In relation to the post-injection treatment effects, both VAS and ODI scores statistically decreased, compared with the pre-injection state. According to the study by Lahat et al. ${ }^{36}$ lidocaine reduces generation of the nuclear factor-kappa B (NF-kB), which is an intracellular signaling protein. In addition it suppresses the proliferation of T-cells, which are involved in immunity and inflammatory reaction, as well as the generation of 
several cytokines, which generate the anti-inflammatory reaction. A study using a rat model of septic peritonitis reported that lidocaine injections reduced concentrations of the TNF $\alpha$ and the keratinocyte-derived chemokine (KC), which are cytokines involved in the plasma inflammatory reactions. ${ }^{37,38}$

It was also reported that lidocaine suppresses the secretion of histamine, which is a vehicle of the inflammatory reaction, from mast cells and also reduces the release of leukotrien B-4 and interleukin 1 from both mononuclear and multinucleated cells. ${ }^{39}$ In addition to the anti-inflammatory reaction, lidocaine works on sodium channels to block the nociceptive pain pathway and nerve conduction via the spinal dorsal root ganglion, thus further relieving pain. ${ }^{40}$ Therefore, lidocaine injections can elicit pain relief effects by blocking pain transmission and by affecting the inflammatory reaction and many intracellular signaling proteins.

Although conducted in a prospective randomized design, this study had some limitations. One was that it failed to remove the bias that may occur when assessing the outcome of the patient treatment using a doubleblinded method. Other limitations included a very small number of subjects, as well as not determining a longterm curative value. Moreover, the study targeted only the radicular pain cases among patients with degenerative lumbar scoliosis combined with spinal stenosis. This made us unaware of the treatment effects for back pain and neurogenic claudication. Further studies are required to elucidate such effects.

\section{CONCLUSION}

For patients with degenerative lumbar scoliosis combined with spinal stenosis, steroid injections for radicular pain achieved effective pain relief for three months, compared to lidocaine injections. The transforaminal steroid injection approach can be considered a valid nonsurgical treatment option for radicular pain in patients diagnosed with degenerative lumbar scoliosis.

\section{ACKNOWLEDGEMENTS}

This work was supported by Inje University research grant, 2009.

\section{REFERENCES}

1. Nygaard OP, Mellgren SI, Osterud B. The inflammatory properties of contained and noncontained lumbar disc herniation. Spine 1997; 22: 2484-2488

2. Franson RC, Saal JS, Saal JA. Human disc phospholipase A2 is inflammatory. Spine 1992; 17 Suppl 6: S129-132

3. Olmarker K, Blomquist J, Stromberg J, Nannmark U, Thomsen P, Rydevik B. Inflammatogenic properties of nucleus pulposus. Spine 1995; 20: 665-669

4. Rydevik B, Brown MD, Lundborg G. Pathoanatomy and pathophysiology of nerve root compression. Spine 1984; 9: 7-15

5. Olmarker K, Redevik B, Holm S. Edema formation in spinal nerve roots induced by experimental, graded compression. An experimental study on the pig cauda equina with special reference to differences in effects between rapid and slow onset of compression. Spine 1989; 14: 569-573

6. Lutz GE, Vad VB, Wisneski RJ. Fluoroscopic transforaminal lumbar epidural steroids: an outcome study. Arch Phys Med Rehabil 1998; 79: 1362-1366

7. Cooper G, Lutz GE, Boachie-Adjei O, Lin J. Effectiveness of transforaminal epidural steroid injections in patients with degenerative lumbar scoliotic stenosis and radiculopathy. Pain Physician 2004; 7: 311-317

8. Vad VB, Bhat AL, Lutz GE, Cammisa F. Transforaminal epidural steroid injections in lumbosacral radiculopathy: a prospective randomized study. Spine 2002; 27: 11-16

9. Kostuik JP, Bentivoglio J. The incidence of low backpain in adult scoliosis. Spine 1981; 6: 268-273

10. Robin GC, Span Y, Steinberg R, Makin M, Menczel J. Scoliosis in the elderly: a follow- up study. Spine 1982; 7: 355-359

11. Dawson E, Bernbeck J. The surgical treatment of low back pain. Phys Med Reh abil Clin N Am 1998; 9: 489495

12. Nasca RJ. Rationale for spinal fusion in lumbar sipnal stenosis. Spine 1989; 14: 451-454

13. Simotas AC, Dorey FJ, Hansraj KK, Cammisa F Jr. Nonoperative treatment for lumbar spinal stenosis. Clinical and outcome results and a 3-year survivorship analysis. Spine 2000; 25: 197-203

14. Nash CL Jr, Moe JH. A study of vertebral rotation. J 
Bone Joint Surg Am 1969; 51: 223-229

15. Schwab FJ, Smith VA, Biserni M, Gamez L, Farcy JP, Pagala M. Adult scoliosis: a quantitative radiographic and clinical analysis. Spine 2002; 27: 387-392

16. Grubb SA, Lipscomb HJ. Diagnostic findings in painful adult scoliosis. Spine 1992; 17: 518-527

17. Grubb SA, Lipscomb HJ, Coonrad RW. Degenerative adult onset scoliosis. Spine 1988; 13: 241-245

18. Grubb SA, Lipscomb HJ, Suh PB. Results of surgical treatment of painful adult scoliosis. Spine 1994; 19: 1619-1627

19. Jackson RP, McManus AC. Radiographic analysis of sagittal plane alignment and balance in standing volunteers and patients with low back pain matched for age,sex, and size. A prospective controlled clinical study. Spine 1994; 19: 1611-1618

20. Kantrowitz F, Robinson DR, McGuire MB, Levine L. Corticosteroids inhibit prostaglandin production by rheumatoid synovia. Nature 1975; 258: 737-739

21. Fukusaki M, Kobayashi I, Hara T, Sumikawa K. Symptoms of spinal stenosis do not improve after epidural steroid injection. Clin J Pain 1998; 14: 148-151

22. Johansson A, Hao J, Sjolund B. Local corticosteroid application blocks transmission in normal nociceptor C-fibres. Acta Anaesthesiol Scand 1990; 34: 335-338

23. Hoogmartens M, Morelle P. Epidural injection in the treatment of spinal stenosis. Acta Orthop Belg 1987; 53: 409-411

24. Rosen CD, Kahanovitz N, Bernstein R, Viola K. A retrospective analysis of the efficacy of epidural steroid injections. Clin Orthop 1988; 228: 270-272

25. Delport EG, Cucuzzella AR, Marley JK, Pruitt CM, Fisher JR. Treatment of lumbar spinal stenosis with epidural steroid injections: a retrospective outcome study. Arch Phys Med Rehabil 2004; 85: 479-484

26. Riew KD, Yin Y, Gilula L, Bridwell KH, Lenke LG, Lauryssen C, Goette K. The effect of nerve-root injections on the need for operative treatment of lumbar radicular pain. A prospective, randomized, controlled, double-blind study. J Bone Joint Surg Am 2000; 82: 1589-1593

27. Cannon DT, Aprill CN. Lumbosacral epidural steroid injections. Arch Phys Med Rehabil 2000; 81 Suppl 1: S87-98

28. Miyamoto H, Sumi M, Uno K, Tadokoro K, Mizuno K. Clinical outcome of nonoperative treatment for lum- bar spinal stenosis, and predictive factors relating to prognosis, in a 5 -year minimum follow-up. J Spinal Disord Tech 2008; 21: 563-568

29. van Dam BE. Nonoperative treatment of adult scoliosis. Scoliosis Orthop Clin North Am 1988; 19: 347-351

30. Pritchett JW, Bortel DT. Degenerative symptomatic lumbar scoliosis. Spine 1993; 18: 700-703

31. Ng L, Chaudhary N, Sell P. The efficacy of corticosteroids in periradicular infiltration for chronic radicular pain: a randomized, double-blind, controlled trial. Spine 2005; 30: 857-862

32. Kluba T, Dikmenli G, Dietz K, Giehl JP, Niemeyer T. Comparison of surgical and conservative treatment for degenerative lumbar scoliosis. Arch Orthop Trauma Surg 2009; 129: 1-5

33. Irwin ZN, Hilibrand A, Gustavel M, McLain R, ShaVer W, Myers M, Glaser J, Hart RA. Variations in surgical decision making for degenerative spinal disorders. Part 1: lumbar spine. Spine 2005; 30: 2208-2213

34. Swezey RL. Outcome for lumbar stenosis. J Clin Rheumatol 1996; 2: 129-134

35. Onel D, Sari H, Donmez C. Lumbar spinal stenosis: clinical/radiologic therapeutic evaluation in 145 patients. Conservative treatment or surgical intervention? Spine 1993; 18: 291-298

36. Lahat A, Ben-Horin S, Lang A, Fudim E, Picard O, Chowers Y. Lidocaine down-regulates nuclear factorkappaB signalling and inhibits cytokine production and T cell proliferation. Clin Exp Immunol 2008; 152: 320-327

37. Gallos G, Jones DR, Nasr SH, Emala CW, Lee HT. Local anesthetics reduce mortality and protect against renal and hepatic dysfunction in murine septic peritonitis. Anesthesiology 2004; 101: 902-911

38. Cassuto J, Sinclair R, Bonderovic M. Anti-inflammatory properties of local anesthetics and their present and potential clinical implications. Acta Anaesthesiol Scand 2006; 50: 265-282

39. Johnson HG, Miller MD. Inhibition of histamine release and ionophore-induced calcium flux in rat mast cells by lidocaine and chlorpromazine. Agents Actions 1979; 9: 239-243

40. Devor M, Wall PD, Catalan N. Systemic lidocaine silences ectopic neuroma and DRG discharge without blocking nerve conduction. Pain 1992; 48: 261-268 